\title{
Urgent needs for multidisciplinary and transdisciplinary research
}

\author{
Sven Erik Jørgensen ${ }^{1}$ \\ ${ }^{1}$ Department of Analytical Biosciences, Copenhagen University, University Park 2, 2100 Copenhagen, Denmark
}

Received: 25 January 2016/Revised: 15 February 2016/Accepted: 16 February 2016/Published online: 27 February 2016 (C) Joint Center on Global Change and Earth System Science of the University of Maryland and Beijing Normal University and Springer-Verlag Berlin Heidelberg 2016

\begin{abstract}
Traditional methods based on mono-disciplinary research or economic growth models cannot solve linked and diversified environmental problems. It requires a holistic view to understand the network of problems and how they are interrelated. In this regard, multidisciplinary and transdisciplinary approaches and models are urgently needed. This paper demonstrates that for ten problems, including population growth, poverty, inequality, wars, refugees, famine, pollution, global warming, loss of nature, and depletion of resources, are interconnected. An integration of the use of eight toolboxes (the energy toolbox, the environment toolbox, the ecology toolbox, pollution control, Pigovian tax, aids to developing countries education and research and family planning) is proposed to provide holistic solutions to examine the networks of complex problems. Due to the linkage of global problems, problems that can be solved directly by toolboxes may result in partially and indirectly settlement of other problems. It should be emphasized that uses of integrated solutions based on several toolboxes are needed to solve the many interacting global problems that we are confronted with.
\end{abstract}

Keywords Network - Multidisciplinary · Transdisciplinary $\cdot$ Global model $\cdot$ Toolbox

\section{Introduction}

Humans are confronted with a series of very serious problems: poverty, increased inequalities among countries and people, refugees, regional conflicts, flooding and

Sven Erik Jørgensen

msijapan@hotmail.com draught, famine, civil wars, global climate change, faster and faster exploitation of the global non-renewable and renewable resources, rapid land use change and urbanization, and increased emissions of harmful chemicals into the environment. History has shown us that we cannot solve these problems using either traditional methods based on narrow mono-disciplinary research or following the shortsighted economic a growth model. Additionally, we know from natural laws that continuous growth in a finite environment as the Earth is impossible. The core question is: How can we ensure sustainable development for the societies on Earth? The problem is rooted in the fact, that the above-listed problems are interrelated. If you solve one problem you may reinforce another problem. If you for instance solve the famine due to drought problems by expansion of the agricultural area on the expense on nature by deforestation, natural ecosystems are destructed and the indispensable ecosystem services offered by the natural ecosystem are lost forever. It will create poverty, depletion of resources, and pollution problems. In the case of deforestation, the removal process of carbon dioxide is lost, the process purifying air and water is lost, the timber production is lost, and the biodiversity is reduced. An alternative solution could solve the drought and associated famine problem by a multidisciplinary solution. By use of solar cells, it would possible to provide renewable energy to produce freshwater from saline water and use the water for irrigation, to produce more agricultural products by use of irrigation and by use of the water of course prudently and to provide a higher yield at the same land and get more crops per drops. To find alternative solutions, that solve more problems at the same time or at least not create new problems when a problem is solved, requires that we can 
overview all the problems and see so to say the forest through the trees. It requires a holistic view drawing on our ability to understand the network of problems and how they are interrelated. Intensive use of multidisciplinary and transdisciplinary approaches and models combined with new creative ideas are urgently needed in this context.

Several of the listed problems are environmental problems, although not all of them. The environmental problems are flooding and draught, famine, global climate change, faster and faster exploitation of the global nonrenewable and renewable resources, rapid land use change and urbanization, and increased emissions of harmful chemicals into the environment, but these problems may have an indirect effect on all the other listed problems. When the urgent needs for multidisciplinary and transdisciplinary approaches are discussed, the environmental problems and their possible solutions can be used as illustrations. It has already been completely acknowledged that most environmental problems cannot be solved without a multidisciplinary and transdisciplinary approach. In this context, it can be mentioned that Jørgensen and Nielsen (2012) and Jørgensen et al. (2016) have advocated for the use of integrated ecological, environmental management, where seven steps are needed:

1. Define the problem. It requires the use of environmental science.

2. Determine the ecosystems involved and their properties. It requires the use of systems ecology.

3. Find and quantify the sources to the problem. It requires the use of engineering disciplines, biology, physics, and chemistry.

4. Set up a diagnosis to understand the relation between the problem and the sources. As diagnostic tools we have ecological modeling, ecological indicators, and ecosystem services.

5. Determine all the tools we need to implement to solve the problem. A good overview of environmental technology, ecotechnology, cleaner technology, and environmental legislation is needed.

6. Identify measures and take proper action, like remediation, mitigation or the use of a suitable combination of the possibilities mentioned in point 5 .

7. Follow the recovery process by preferably a wide monitoring program. It is necessary to follow this step to have sufficient knowledge of analytical biosciences and chemistry.

All by all, integrated ecological-environmental management is based on a multidisciplinary fundament. It is, furthermore, clear when we include socioeconomic problems even more disciplines are needed and the integration of the disciplines makes the approach transdisciplinary, particularly when it is acknowledged that the problems that we confronted with are interrelated. The conclusion is that a properly working solution to the above-listed problems that humans will meet at an increasing strength the coming years and decades requires a super-holistic view, which probably is only possible to establish by a very well cooperating multidisciplinary team, representing at least the most important of the needed cooperative disciplines. The often narrow minded political solutions cannot cope with these problems, as the politicians inevitably have sectional interests and cannot provide the super-holistic view needed to capture and combine all the problems simultaneously. When it, furthermore, is considered that the economy is the dominant factor in most political decisions today, then it becomes clear that the conflict is not only the reductionistic view contra the holistic view but also the short-sighted versus the long-term considerations, because economy is not stable due to enormous variability in the economic factors-take just the interest rate as example - to consider a time horizon of more than 2-3 at the most 5 years that is of course far too short a period for the solutions of the serious global problems listed above.

\section{E3 and model}

The journal E3 has been launched to develop and enhance multidisciplinary research to be able to develop integrated solutions to the complex of problems that we are confronted with. E3 means that we need at least to apply research, knowledge, and models that are based on energy, environment, and ecology.

Let us denote the research results, knowledge, and models that we have available today from these three areas for the energy toolbox, the environment toolbox, and the ecology toolbox. An integration of the use of these three toolboxes will be able to provide holistic solutions to at least most of the problems listed in the Introduction, if not directly then at least partially and indirectly. It does not imply that all the problems are completely solved by these three toolboxes. It would most probably need use of additional toolboxes, as we will be discussed in the next section. Figure 1 shows the listed problems and how they are linked and which problems that can be solved directly by the three toolboxes (indicated with red rings), which due to the links implies that the other problems are at least solved partially and indirectly. The toolbox energy proposes the use of renewable energy, that will solve the global warming problems and the related pollution problem, but this toolbox will also focus on loss of nature, because it is important to reduce loss of nature due to its ability of take up carbon dioxide. The toolbox environment has tools to abate pollution and global warming and in addition loss of nature and depletion of resources- two 
Fig. 1 Listed problems are linked as shown. For instance global warming is linked to refugees, famine, depletion of resources, loss of nature and inequality, which are consequences of global warming and pollution and loss of nature on the other hand increases the global warming. The three shown toolboxes, energy, environment, and ecology can be used to solve the problems of pollution, global warming, loss of nature and depletion of resources, and thereby partially and indirectly the other problems

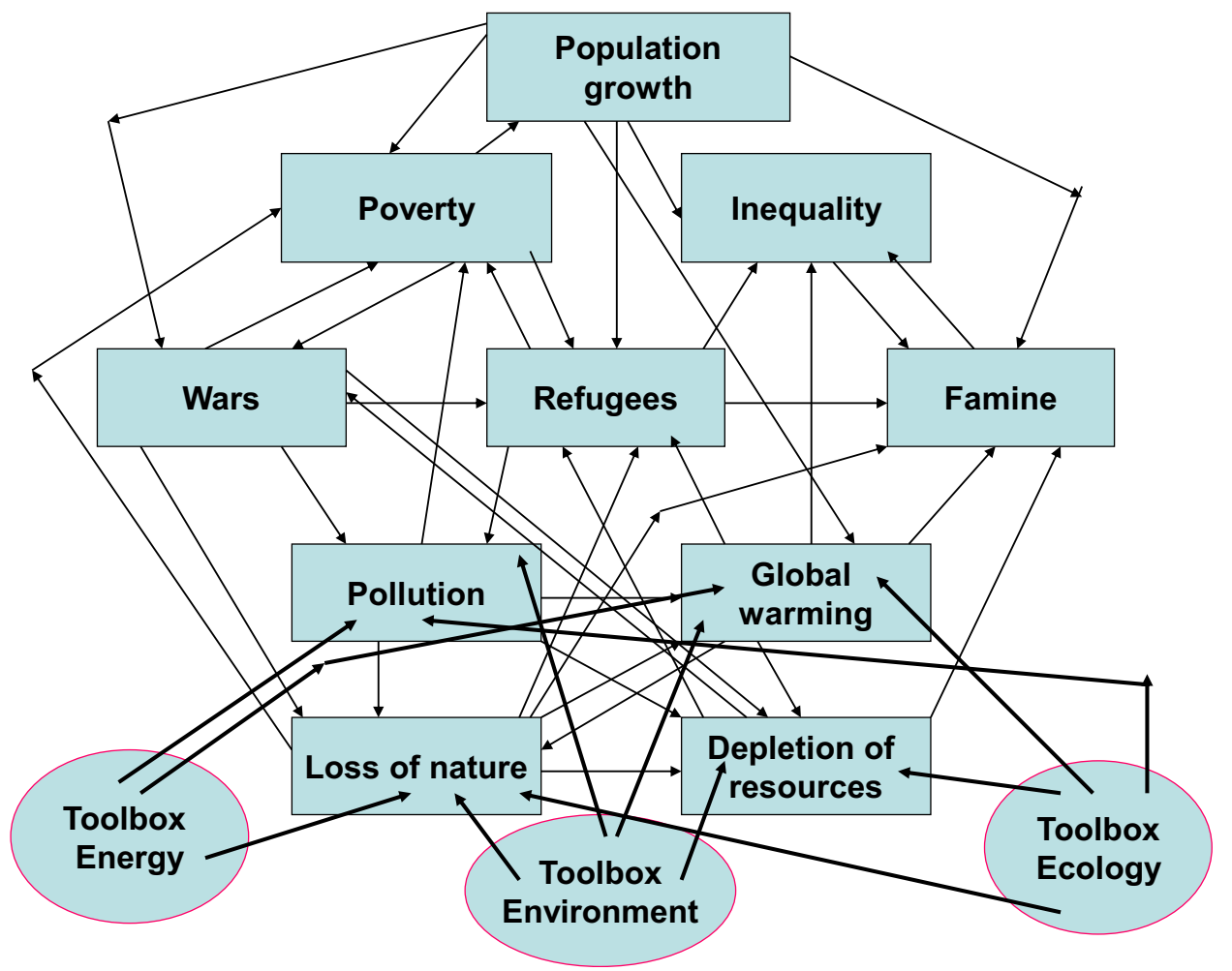

very closely related problems. The toolbox ecology will use the ecological sub-disciplines to find solution to reduce pollution and loss of nature, for instance by ecological engineering methods and reduce the global warming and the depletion of resources by erection and recovery of ecosystems.

The problems form a network, and as we know from ecological network theory, all components in a network have effect on each other and that the indirect effect may be bigger than the direct effect. It is therefore important to understand the network of problems and which factors determine the interactions between the components of the network. The connectivity in the network of problems is actually similar to ecological networks because there are 36 links out of 90 possible or the connectivity is 0.4 or $40 \%$. The challenge is to build a model of the network in Fig. 1 and be able to quantify the results of using the E3 toolboxes on different levels. It could be a first step toward a much more integrated model and very integrated environmental management. There are probably available statistically supported equations that would make it possible to quantify the various links between the problems. The journal will of course welcome the submission of papers presenting such integrated ecological-environmental management models, which could be developed similarly to the development of ecological models. It would be interesting to examine whether such models actually follow the network properties of ecological networks presented by Patten (2016), which would be possible to give better directions for the management and the effects of using the E3 toolboxes could be increased.

\section{Solutions of the global problems}

A similar approach as proposed above to use toolboxes or several specific actions as tools to solve problems that are linked in more or less complex networks, has been used in a recent book, Jørgensen et al. (2015). The model simulates the global development in the twenty-first century, starting year 2000. The global model similarly to the one proposed by the Club of Rome, Meadows et al. (1972, 2004); see Fig. 2, was used. The model has eight state variables, namely

1. The production capacity of the industrialized countries, denoted CAPI. Meadows et al. (1972) applies a reference industrial potential in year 1962 of 100 with $75 \%$ in the industrialized countries and $25 \%$ in the developing countries. Under this scenario, the increase that has taken place since 1962 is the initial value for year 2000, such that CAPI $=340$.

2. The production capacity of the developing countries, CAPD, has an initial value in year $2000=110$ according to the reference in 1962 as indicated above.

3. The pollution level, POLL, has an initial value for year 2000 of 100 . This is a relative value that increases with 


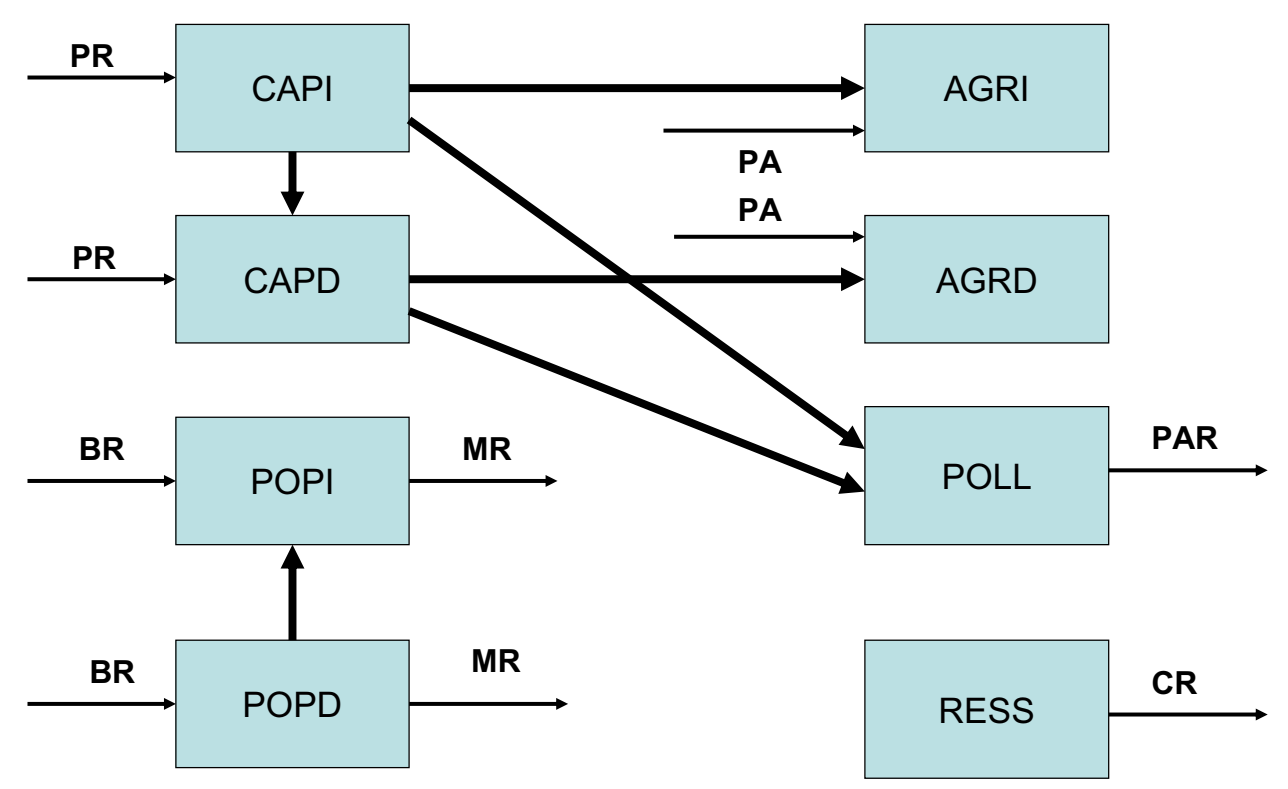

Fig. 2 Simplified conceptual diagram. Only the eight state variables, the direct inputs and outputs, and the transfers are shown, but not the controls. In addition, all the state variables have several important controls of rates by the other state variables; see the details about the model in Jørgensen et al. (2015). The annual increase in the production capacities, also denoted the interest rate, are indicated as PR. BR and MR are birth rate and mortality rate regulating the population size. PA indicates the increase in the annual agricultural

the production level and decreases with pollution abatement.

4. The available resources, RESS, has an initial value of 20,000 , which corresponds to about 200 years of consumption with the present initial rate of using resources and about 100 years with the expected average value of using the resources during the twenty-first century, based on business as usual. An annual increase in resource use of about $1.5 \%$ is presumed, when the resources will be depleted in about 100 years.

5. The annual agricultural production capacity in the developing countries, AGRD, is by year 2000 defined as 100. This initial production is on the order of 20-25\% lower than needed to give the entire present population in the developing countries a sufficient diet both quantitatively and qualitatively.

6. The annual agricultural production capacity in the industrialized countries, AGRI, has also a relative value 100 in year 2000 .

7. The population in the developing countries, POPD, which is 5000 million in year 2000, of which 300 are included in the population of the industrialized countries, because the United Nations statistics indicate for year 2000 that approximately 300 million, particularly in the BRIC countries have a standard of living, birth production of the industrialized and the developing countries. The pollution level increases proportional to the production (PR) and decreases due to pollution abatement (PAR); CR is the annual reduction in the resources. The development of the state variables is furthermore determined by forcing functions or external variables. They are the toolboxes and the actions we use to change the development of the state variables. They are listed below

rate, mortality rate, and consumption on the same level as the industrialized countries. Therefore, POPD in year 2000 is equal to 4700 million.

8. The population in the industrialized countries, POPI, in year 2000 is 1000 million (North America, Europe, Japan, Australia, and New Zealand) plus 300 million to account for the middle-class population in the BRIC countries, for a total of 1300 million people.

Production in the developing countries is increasing slightly every year to express that it is easier to increase production on a low level than on a high level. The production capacities, CAPI and CAPD, are presumed to give an interest rate of $7.5 \%$, which is the same rate as applied in Limits to Growth and also about the same as in the book 2052 by J. Randers (see Randers 2012). This means that the production capacity is giving an annual income in both the industrialized and developing countries by $7.5 \%$, provided that we do not consider other factors influencing the production capacity. The rate is, however, increased by investment in education and decreased with pollution level increase and reduction in resources. The increase in the annual agricultural production is considered financed by the annual income of the production capacity.

- Likewise, consumption decreases over time slightly in the industrialized countries because they are closer to 
the saturation and increases over time slightly for the developing countries as they have a significant need for a higher consumption. This interest rate is used 0.65 times in both the industrialized and in the developing countries for consumption (food, cloths, cars, housing, heating, electricity, other goods, and so on).

- The interest rate is furthermore used to cover the costs of the pollution abatement and the investment in education, innovation, and research. Further details of the model see Jørgensen et al. (2015).

The model is used to see the development differences between "business as usual" and the use of a series of actions or toolboxes that aim toward a solution of the global problems. The business as usual is based on the global conditions as a result of political decisions. The conditions are:

- A Pigovian tax rate of $2.2 \%$ is applied. This level is used in many industrial countries today, although the average is probably slightly higher, close $3 \%$.

- The investment in education, innovation, and research is $5 \%$ of GNP, which is a reasonable estimation of the average in the industrialized countries today

- Pollution abatement is $1 \%$ of the GNP

- Only $0.2 \%$ of the GNP is used for support of the developing countries

- Only $2 \%$ of the aid is used for education and innovation in the developing countries which is very close the present situation as far as it has been possible to obtain the information. Practically no money is used for birth control in the developing countries. A small amount is used in a few countries for instance India. It is more or less the situation year 2000, the starting year of the model simulations.

The following actions have been tested to see to what extent they could change the direction of development:

1. All industrialized countries with a GNP/capita of more than 20,000 dollars per year pay $0.8 \%$ of GNP increasing by $0.04 \%$ per year.

2. $10 \%$ of this support is used for family planning.

3. $40 \%$ of the support is used to improve education in the developing countries, while the remaining $50 \%$ is negotiated between the donor and the receptor country. Particularly, education in better agricultural management is urgently needed. The agricultural yield per ha in many developing countries could easily be increased a factor 2-3 or even 4, which would reduce the poverty in many developing countries significantly without increasing the agricultural area.

By the actions $1-3$, the GNP per year and per capita in the developing countries will increase, which will have a significant positive effect on reducing the birth rate in the developing countries according to the UN statistical information (Jørgensen 1994). The birth rate declines by $4 \%$, relatively, starting with a birth rate of 4.4 per 100 inhabitants per year, for every $\$ 1000$ the GNP per capita and year is increased.

4. $2.5 \%$ of the production value is allocated to pollution control. This investment is assumed to be sufficient to control the pollution, and has a positive effect on resource maintenance. It is assumed that pollution is proportional to the production value by a factor (parameter) 0.05 . Or expressed differently, if the production value increases 100 units, then the pollution increases 5 units.

5. The Pigovian (green) tax is increased to $8 \%$ on average. This tax promotes efficiency and increased recycling and reuse. The effect snowballs because recycling technology is presumed to increase. The pollution abatement has an annual increase which is slightly dependent on the tax rate, because increased recycling and reuse imply inevitably less pollution.

6. A massive investment, at least $10 \%$ of GNP, is made in education, innovation, and research in the industrialized countries, which has a positive impact on production as well as application of the three R's, and thereby on the maintenance of resources. The effect is in accordance with UN statistics.

The impacts on these changes on the development of the eight state variables are based upon statistical information (see Jørgensen et al. 2015)

It not possible to give more details about the results of this global model and the comparison between "business as usual" and the six-point action in this paper, but for more information see reference to Jørgensen et al. (2015). A brief overview of the results is, however, presented in Table 1.

It is clear from the results of this global model that the six-point action plan has a very significant effect on the global development. The next obvious question is, however, to ask: "does the six-point action plan solve the network of problems presented in Fig. 1"? It is certain from the results, that the action plan solves the problems of population growth, poverty, pollution, famine and depletion of the resources directly, but how will the partial or more complete solutions of these problems affect the other problems? To answer these problems we need to develop a model, see Fig. 3, which in principles is similar to the one in Fig. 1. It means that we need to quantify the interactions among the 10 problems, which was also the challenge of course for development of the model shown in Fig. 1. A 
Table 1 Results of the global model applied on two scenarios: business as usual and the sixpoint action plan (The initial values at year 2000 are indicated)

\begin{tabular}{|c|c|c|c|c|c|}
\hline \multirow[t]{2}{*}{ State variables } & \multirow[t]{2}{*}{ Year 2000} & \multicolumn{2}{|c|}{ Business as usual } & \multicolumn{2}{|c|}{ Six-point action plan } \\
\hline & & 2050 & 2100 & 2050 & 2100 \\
\hline POLL & 100 & 142 & 180 & 122 & 104 \\
\hline RESS & 20,000 & 18,000 & 16,800 & 19,400 & 18,800 \\
\hline POPI $\left(10^{6}\right)$ & 1300 & 1500 & 1800 & 1590 & 1900 \\
\hline $\operatorname{POPD}\left(10^{6}\right)$ & 4700 & 9000 & 14,800 & 6800 & 3800 \\
\hline GNP\$/cap dec C & 2850 & 550 & 2180 & 3200 & 19,000 \\
\hline GNP\$/cap ind. C & 25,000 & 17,500 & 3450 & 32,000 & 44,400 \\
\hline
\end{tabular}

Fig. 3 The ten interrelated global problems are shown and the effect of the six-point action plan is indicated by thicker arrows. The action plan corresponds to the five toolboxes shown (indicated with red rings), pollution control, pigovian (green) tax, aids to developing countries, education and research, and family planning. Notice that the five toolboxes are able to solve other of the global problems than the E3 toolboxes, which means that all eight toolboxes supplement each other

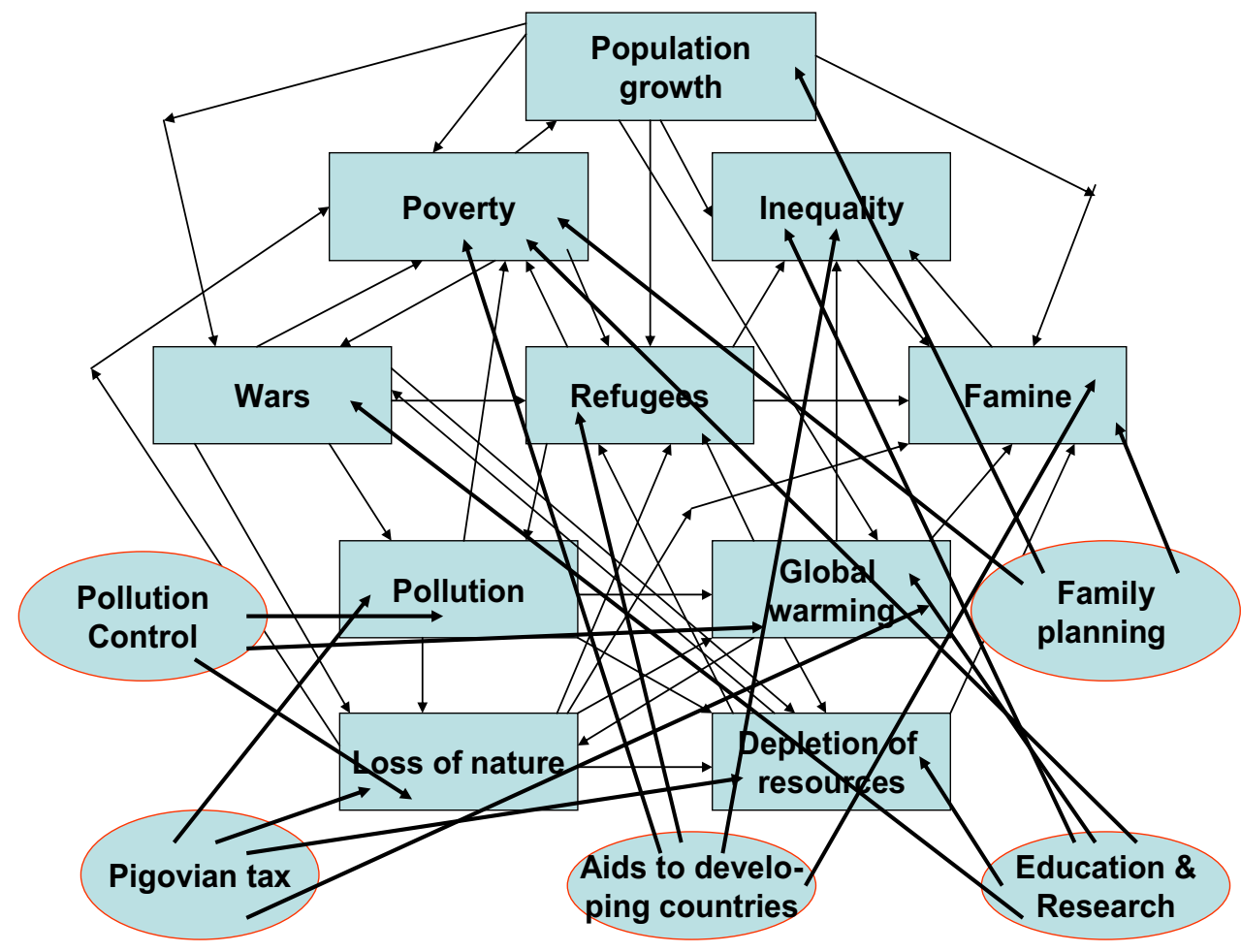

quantification on how the use of the toolboxes partially or completely solve the problems is of course also needed for the development of this model as it is the case for the model in Fig. 1 using the E3 toolboxes. Some of the quantifications have been used in the global model published in Jørgensen et al. (2015), but the concrete model development will reveal to what extent it is needed to introduce additional quantification (which is most probable) to be able to apply the model for simulations.

It would be interesting to develop a model for the interactions of the ten problems and apply simultaneously the E3 toolboxes and the five toolboxes presented in Fig. 3. It is hypothesized at this stage that the eight toolboxes together will solve the problems completely or closed to completely, but it is the challenge to demonstrate it by development of a model combining Figs. 1 and 3.

\section{Summary and conclusions}

The journal E3 wants to emphasize that uses of integrated solutions based on several tool boxes are needed to solve the many interacting global problems that we are confronted with. The global problems are linked and a holistic solution based on an overview of all the linked problems and all the available tool boxes is required. It has been clearly demonstrated in this paper, where it has been discussed that the ten problems are interconnected and that we need to understand the interconnections and use all eight tool boxes simultaneously.

The journal welcomes publications focusing on integrated approaches, models, networks of complex problems and examinations of holistic solutions to the global problems. It implies that multidisciplinary and transdisciplinary 
approaches will be used extensively, which the journal has fully acknowledged and strongly support.

\section{References}

Jørgensen SE (1994) The application of global models for comparison of different strategies on sustainable living. Ecol Econ 11(1):1-8 Jørgensen SE, Nielsen SN (2012) Tool boxes for an integrated ecological and environmental management. Ecol Indic 21:104-109

Jørgensen SE, Fath BD, Nielsen SN, Pulselli F, Fiscus DA, Bastianoni S (2015) Flourishing within limits to growth: following nature's way. Earthscan, Routledge, Oxford
Jørgensen SE, Marques JC, Nielsen SN (2016) Integrated environmental management: a transdisciplinary approach. CRC, Boca Raton

Meadows DH, Meadows DL, Randers J, Behrens WW (1972) The limits to growth. A report for the club of Rome's project on the predicament of mankind. Potomac Associates Book, New York

Meadows DH, Randers J, Meadows DL (2004) Limits to growth: the 30-year update. Chelsea Green Publishing Company, White River Junction

Patten BC (2016) The cardinal hypotheses of holoecology: facets for a general systems theory of the organism-environment relationship. Ecol Model 319:63-111

Randers J (2012) 2052: a global forecast for the next 40 years. Chelsea Green Publishng, White River Junction 